\title{
On the relative advantage of cooperatives
}

\author{
Svend Albæk and Christian Schultz* \\ University of Copenhagen
}

December 16, 1997

\begin{abstract}
We show that the fact that farmers in a cooperative individually decide how much to supply to the cooperative may serve as a commitment device for credibly (and profitably) gaining market share in competition with a profit maximizing firm.
\end{abstract}

JEL L22, Q13

Keywords: cooperatives, commitment

\section{Introduction}

Farmers' manufacturing cooperatives have been very successful in many countries. In Denmark, there has been a continuous process of mergers leading to ever larger cooperatives with more and more members. Furthermore, during this process traditional profit maximizing firms have in many industries been

\footnotetext{
${ }^{*}$ Corresponding author: Christian Schultz, Institute of Economics, University of Copenhagen, Studiestræde 6, DK-1455 Copenhagen K, Denmark. Ph: +45 35323039; fax: +45 35323000; e-mail: christian.schultz@econ.ku.dk.
} 
gradually driven out of business or taken over by the cooperative sector (see, e.g., Bjørn, 1986).

On the other hand it is often claimed that cooperatives are inefficient since they tend to produce too much. Many cooperatives have the rule that the individual farmers themselves decide how much to deliver to the cooperative. The cooperative is thus not in control of its input decision. If the cooperative faces a decreasing demand curve, it will tend to overproduce. The reason is the simple that although an individual farmer may realize that an increase in production will decrease the price in the final market, he only internalizes his own part of the profit loss stemming from the price decrease. From a formal point of view this is similar to what happens in a Cournot oligopoly. The firms in a Cournot market produce too much relative to monopoly production, exactly because they do not internalize the profit losses that the other firms suffer from a price decrease.

However, in a Cournot market there is an advantage to committing to a high production level since production levels are strategic substitutes. If a firm can push its reaction function outwards, e.g. by employing a manager whose salary depends on sales rather than profits, then this firm may gain since the other firms in the industry react by decreasing production, see e.g. the papers by Vickers (1985) and Fershtman and Judd (1987). In this paper we show that a similar mechanism is at play in a market where a cooperative faces an ordinary profit maximizing firm. Since the members of the cooperative do not internalize the profit loss incurred by other members when they increase production, the organization of the cooperative acts like a commitment device for pushing the reaction function of the cooperative outwards, and in the resulting equilibrium the profit maximizing firm ends 
up producing less. ${ }^{1}$ Hence the market share of the cooperative is larger than it would have been if the cooperative maximized the total profit of its members. Furthermore, we show that in our model the members of the cooperative will earn more than the vertically integrated profit per farmer generated in the profit maximizing firm.

The organization of the paper is as follows. Section 2 presents the model. Section 3 investigates the equilibrium and Section 4 concludes.

\section{The model}

We conceive of a market for a final good, where the price, $p$, is given by the inverse demand function

$$
p=a-Q
$$

where $a$ is positive and total supply is $Q$. The product is produced on individual farms, delivered to a manufacturer, who sells it on the market. As an example think of milk. There are $n$ farmers each producing the product on their farms. The cost function of a farmer producing $q$ units is

$$
c(q)=\frac{1}{2} c q^{2}
$$

Marginal costs are positive and increasing. For simplicity we assume that all farmers are alike. There are two manufacturers, and a farmer either sells through one or the other. We call one manufacturer the cooperative and the other the profit maximizing firm, for short the firm. We denote by $n_{c}$ the

\footnotetext{
${ }^{1}$ Note that a profit maximizing firm in our model is similar to a merged firm in that a merged firm internalizes the effects of output changes. Our paper is therefore related to the literature on mergers in Cournot oligopoly, see in particular Farrell and Shapiro (1988) and the references therein.
} 
number of members of the cooperative and by $n_{f}=n-n_{c}$ the number of farmers delivering to the firm.

The cooperative works as follows. Each member decides himself on how much milk he wishes to deliver to the cooperative. This is the rule in effect in most Danish, and many other, cooperatives. The farmer is paid a delivery price per unit. The cooperative retains no profit, and for simplicity we assume that is has constant marginal cost, $m c$, which we normalize to zero. The unit price paid to the farmer, $p_{u}$, is then simply the price the cooperative gets in the market

$$
p_{u}=p=a-Q \text {. }
$$

This way of paying the farmers and thus distributing the profit also corresponds to the rule in effect in Danish and many other dairies.

The firm has a contract with the farmers delivering to it. We will assume that there are no hindrance for the parties to write an optimal contract. Hence the profit maximizing firm maximizes the vertically integrated profit of itself and its suppliers. The distribution of this profit is not essential to our argument; one could conceive of all profit ending up with the farmers or some fraction ending up in the firm. For simplicity we assume that the farmers have all bargaining power, so they get the vertically integrated profit.

The cooperative and the firm compete in the market in usual Cournot fashion, so each takes as given the production of the other. Let $Q^{c}$ be the total production of the cooperative and $Q^{f}$ the total production of the firm.

\subsection{The cooperative}

In the cooperative each farmer decides how much he will supply. We assume that farmers are rational and maximize profits. A farmer takes as given the production level chosen by the other farmers in the cooperative and the 
market. Let $q_{i}$ denote the production of farmer $i$, and let $Q_{-i}^{c}$ denote the total production of the other farmers in the cooperative. We can write farmer $i^{\prime} s$ problem as

$$
\max _{q}\left(a-\left(Q^{f}+Q_{-i}^{c}+q\right)\right) q-\frac{1}{2} c q^{2}
$$

The farmer takes into account that if he raises production he will cause the price to fall slightly, but he only internalizes the profit loss this gives himself, not the loss inflicted on the other members of the cooperative. The first order condition is

$$
a-\left(Q^{f}+Q_{-i}^{c}+2 q\right)-c q=0 .
$$

Using that all farmers are alike we have that $q_{i}=q$ for all $i$, and we get

$$
q=\frac{a-Q^{f}}{\left(n_{c}+1\right)+c} .
$$

Hence, the total production of the cooperative is given by the reaction function

$$
Q^{c}=R^{c}\left(Q^{f}\right) \equiv \frac{n_{c}\left(a-Q^{f}\right)}{\left(n_{c}+1\right)+c}
$$

\subsection{The profit maximizing firm}

The firm takes into account that a single farmer's increased production causes the price to fall and that this hurts all farmers associated with the firm. As mentioned above, we assume that the firm chooses a production level which maximizes the vertically integrated profit of the firm and the farmers supplying it. Hence, the firm, and not the individual farmers, is in control of how much each farmer supplies. Evidently, because of increasing marginal costs, the optimal solution involves each farmer producing the same quantity. The problem of the firm is then

$$
\max _{Q}\left(a-\left(Q^{c}+Q\right)\right) Q-n_{f} \frac{1}{2} c\left(\frac{Q}{n_{f}}\right)^{2}
$$


and the solution is

$$
Q^{f}=R^{f}\left(Q^{c}\right) \equiv \frac{a-Q^{c}}{2+\frac{1}{n_{f}} c}
$$

\section{Equilibrium}

In equilibrium the production levels of the cooperative and the firm are best replies to each other. Denoting the equilibrium levels $Q^{c *}$ and $Q^{f *}$, respectively, we have

$$
Q^{c *}=R^{c}\left(Q^{f *}\right) \text { and } Q^{f *}=R^{c}\left(Q^{c *}\right) \text {. }
$$

Solving for the equilibrium we get

$$
\begin{aligned}
Q^{f *} & =a n_{f}(1+c) K \\
Q^{c *} & =a n_{c}\left(n_{f}+c\right) K
\end{aligned}
$$

where

$$
K \equiv \frac{1}{n_{f} n_{c}+n_{c} c+2 n_{f}+c+2 c n_{f}+c^{2}} .
$$

Production, and therefore the market share, per farmer is higher for the cooperative than for the firm, as long as $n_{f}>1$. Since marginal costs are increasing, this could in principle be associated with the members of the cooperative earning less profit. This is not the case. The profit of a cooperative farmer is

$\pi^{c}=\left(a-\left(a n_{f}(1+c) K+a n_{c}\left(n_{f}+c\right) K\right)\right) a\left(n_{f}+c\right) K-\frac{1}{2} c\left(a\left(n_{f}+c\right) K\right)^{2}$

while that of a farmer supplying the firm

$\pi^{f}=\left(a-\left(a n_{f}(1+c) K+a n_{c}\left(n_{f}+c\right) K\right)\right)(a(1+c) K)-\frac{1}{2} c(a(1+c) K)^{2}$.

Being in the cooperative is more profitable if

$$
\pi^{c}>\pi^{f}
$$


Inserting for $K$ and rearranging we get that this is equivalent to

$$
(2+c)\left(n_{f}+c\right)^{2}>(1+c)^{2}\left(c+2 n_{f}\right)
$$

which is fulfilled for all $n_{f}>1^{2}$. Thus being in the cooperative is always more profitable if the firm has more than one farmer supplying it; if there is only one farmer supplying the firm this farmer is acting exactly like the members of the cooperative, and his profit is therefore also the same. If more than one farmer supply the firm they, however, earn less than the members of the cooperative.

\section{Conclusion}

Our result contributes to an understanding of why cooperatives have been so successful even though they have been in competition with profit maximizing firms. Note, that in our model the cooperative makes more profit at the expense of the profit maximizing firm. This does not contradict the often heard criticism that cooperatives produce too much so that it would be to the benefit of all farmers to decrease production. In a market with only profit maximizing firms each farmer would generate more profit per head than in a market with cooperatives. In a sense, there is a prisoner's dilemma situation. Consider a market with two firms: given the organization of the other firm, profit maximizing or cooperative, the best organization for a firm is cooperative. Hence, a Nash equilibrium in organizational structure have both firms choose cooperative. Nevertheless, it would be better for both firms if they both were profit maximizing firms.

\footnotetext{
${ }^{2}$ Note, that by setting $c=0$ we let farmers have constant marginal costs. Again, $\pi^{c}>\pi^{f}$ for all $n_{f}>1$.
} 
If one conceives of an evolution of the market structure where an organization earning higher profit per farmer over time attracts more farmers, then the result of this paper suggests that in the long run all farmers would be member of the cooperative. This corresponds rather well to the development in the Danish cooperative sector mentioned above.

\section{References}

Bjørn, C., 1986, Andelssamarbejdet i Danmark (Andelsudvalget, Copenhagen).

Farrell, J. and C. Shapiro, 1990, Horizontal mergers: an equilibrium analysis, American Economic Review, 80, 107-26.

Fershtman, C. and K.I. Judd, 1987, Equilibrium incentives in oligopoly, American Economic Review, 77, 927-940.

Vickers, J., 1985, Delegation and the theory of the firm, Economic Journal, 95 (supplement), 138-147. 